\title{
Espécies de cigarrinhas-das-pastagens (Hemiptera: Cercopidae) no meio-norte do Mato Grosso
}

\author{
Spittlebugs species (Hemiptera: cercopidae) in middle-north of \\ MatoGrosso state, Brazil
}

\author{
Eduardo Roberto de Almeida Bernardo ${ }^{1}$ Vander de Freitas Rocha ${ }^{2}$ \\ Osni Puga $^{3}$ Ricardo Adaime da Silva ${ }^{4}$
}

\begin{abstract}
RESUMO
O objetivo deste trabalho foi identificar as principais espécies de cigarrinhas-das-pastagens que ocorrem em áreas produtoras de bovinos de corte no meio-norte do Estado de Mato Grosso. Foram efetuadas amostragens mensais de cigarrinhas de novembro/1999 a fevereiro/2000 em cinco municipios, encontrando-se as seguintes espécies: Barra do Bugres - Deois flavopicta (87\%) e Mahanarva fimbriolata (13\%); Colider - D. flavopicta (81\%) e M. fimbriolata (19\%); Alta Floresta e São José do Rio Claro - D. flavopicta (72\%) e M. fimbriolata (28\%); Juara - D. flavopicta (51\%), M. fimbriolata (37\%) e Zulia entreriana (12\%).

Palavras-chave: Deois flavopicta, Mahanarva fimbriolata, Zulia entreriana, pastagem.
\end{abstract}

\section{ABSTRACT}

This work was carried out to identify the main spittlebugs species occuring on cattle producing area in MiddleNorth of Mato Grosso State. It were took monthly spittlebugs sampling from November/1999 to February/2000 in five counties, finding the following species: Barra do Bugres Deois flavopicta (87\%) and Mahanarva fimbriolata (13\%); Colider - D. flavopicta (81\%) and M. fimbriolata (19\%); Alta Floresta and São José do Rio Claro - D. flavopicta (72\%) and
M. fimbriolata (28\%); Juara - D. flavopicta (51\%), M. fimbriolata (37\%) and Zulia entreriana (12\%).

Key words: Deois flavopicta, Mahanarva fimbriolata, Zulia entreriana, grassland.

As cigarrinhas-das-pastagens (Hemiptera: Cercopidae), representadas por diferentes gêneros e espécies, são os insetos que causam os maiores prejuízos às pastagens introduzidas no Brasil, principalmente Brachiaria decumbens Stapf e Brachiaria humidicola (Rendle) Schweick, como referem HEWITT (1985), COSENZA et al. (1989) e KOLLER \& HONER (1994).

Estes insetos, particularmente na fase adulta, ao sugarem a seiva da gramínea, injetam uma toxina que interfere na síntese da clorofila (HEWITT, 1988). Em decorrência, ocorre o amarelecimento das folhas, restrição no crescimento da planta, decréscimo na produção de forragem e, em função disso, redução na capacidade de suporte do campo (HEWITT, 1985; HEWITT, 1988). Pesquisas têm demonstrado que os

\footnotetext{
${ }^{1}$ Engenheiro Agrônomo, Mestre em Agronomia, Departamento de Fitossanidade, Faculdade de Ciências Agrárias e Veterinárias, Universidade Estadual Paulista, Via de Acesso Professor Paulo Donato Castellani, s/n, 14880-900, Jaboticabal, SP. E-mail: erabernardo@hotmail.com. Autor para correspondência.

${ }^{2}$ Engenheiro Agrônomo, Mestrando em Agricultura Tropical, UFMT, Cuiabá, MT.

${ }^{3}$ Técnico Agrícola, Estação de Avisos Fitossanitários, São José do Rio Claro, MT.

${ }^{4}$ Engenheiro Agrônomo, Doutor em Entomologia Agrícola, EMBRAPA Amapá, Rod. Juscelino Kubitsheck, km 5, 68903-000, Macapá, AP.
} 
danos provocados pelas cigarrinhas às pastagens variam para cada espécie de gramínea, sendo que os prejuízos econômicos podem atingir cifras alarmantes, dependendo do local, condições climáticas e manejo.

No Brasil Central, a monocultura de pastagens introduzidas tem resultado no aumento populacional desses hemípteros (HEWITT, 1988; COSENZA et al., 1989), cujos prejuízos não se limitam apenas às pastagens, estendendo-se às culturas do arroz, cana-de-açúcar e milho (SANTOS et al., 1982; NILAKHE, 1985). Áreas significativas, ocupadas com arroz e milho, principalmente em Mato Grosso do Sul, Goiás, Minas Gerais e, mais recentemente, Mato Grosso, têm sido infestadas por estas pragas. De modo geral, as cigarrinhas são oriundas de áreas cultivadas com Brachiaria spp. (NILAKHE, 1985), que se constituem no principal substrato para sua alimentação, quando comparadas com outras espécies de gramíneas utilizadas como forrageiras (HEWITT, 1985; COSENZA et al., 1989). Assim, o presente trabalho teve o objetivo de determinar as principais espécies de cigarrinhasdas-pastagens que ocorrem nos principais municípios produtores de bovinos de corte do meio-norte do Estado de Mato Grosso.

Com o auxílio da Delegacia Federal de Agricultura do Estado de Mato Grosso, Setor de Sanidade Vegetal, e sob a coordenação da Estação de Avisos Fitossanitários (EAF) de São José do Rio Claro, MT, foram efetuadas avaliações do número de cigarrinhas em cinco municípios tradicionais na produção de bovinos de corte do meio-norte do Estado. Foram realizadas amostragens mensais, em propriedades agrícolas dos municípios de Barra do Bugres, Colíder, Alta Floresta, São José do Rio Claro e Juara, de novembro de 1999 a fevereiro de 2000 (compreendendo aproximadamente $1.000 .000 \mathrm{de}$ hectares), as quais consistiram na contagem de ninfas e adultos de cada espécie de cigarrinhas presentes nas plantas, em parcelas de $1 \mathrm{~m}^{2}$ de pastagem. Em cada propriedade foram realizadas duas contagens a cada $30 \mathrm{~m}$, em toda a extensão do maior comprimento dos piquetes. Alguns exemplares dos insetos foram coletadas com rede entomológica e enviados ao laboratório da EAF para confirmação da identificação feita em campo. Para cada município foi calculada a média dos percentuais de ocorrência das espécies nas propriedades amostradas.

As áreas amostradas eram compostas predominantemente por Brachiaria brizantha (Hochst. ex A. Rich.) Stapf, sendo uma pastagem bastante adequada para a região, segundo SALERMO et al. (1990).

Três espécies de cigarrinhas-daspastagens foram constatadas: Deois flavopicta (Stal, 1854), Mahanarva fimbriolata (Stal, 1854) e Zulia entreriana (Berg, 1879), sendo a primeira, a de maior ocorrência em todos os municípios. Os percentuais desta espécie em relação aos totais amostrados em cada município chegaram a $87 \%, 81 \%, 72 \%, 72 \%$ e $51 \%$ nos municípios de Barra do Bugres, Colíder, Alta Floresta, São José do Rio Claro e Juara, respectivamente (Tabela 1). A segunda espécie mais representativa foi $\boldsymbol{M}$. fimbriolata, também presente nos cinco municípios, chegando a $37 \%$ do total amostrado em Juara. $\boldsymbol{Z}$. entreriana ocorreu apenas em Juara, correspondendo a $12 \%$ do total amostrado no município.

As três espécies de cigarrinhas-daspastagens amostradas no presente trabalho também foram as mencionadas por KOLLER \& VALÉRIO (1988), em levantamentos realizados em Campo Grande, Mato Grosso do Sul, porém a espécie mais abundante na ocasião foi $\boldsymbol{Z}$. entreriana $(85 \%)$, seguida por $\boldsymbol{D}$. flavopicta (14\%) e M. fimbriolata (1\%).

Os resultados evidenciam a importância de $\boldsymbol{D}$. flavopicta em relação às demais espécies de cigarrinhas-das-pastagens e corroboram a informação de PIRES et al. (2000), de que esta é a espécie predominante nas pastagens cultivadas na região Centro-Oeste do Brasil. Os mesmos autores relacionaram onze espécies de pastagens nativas ou naturalizadas que servem de alimento para $\boldsymbol{D}$. flavopicta, na região de Brasília, Distrito Federal, registrando menores densidades de ninfas no cerrado do que em pastagens cultivadas. Isto demonstra que a introdução de pastagens exóticas, especialmente Brachiaria spp., oriundas da África, favoreceu o

Tabela 1 - Número de propriedades amostradas, total de amostras, total de indivíduos (ninfas + adultos) e percentual das espécies de cigarrinhas-das-pastagens amostradas em pastagens de diferentes municípios de Mato Grosso, de novembro de 1999 a fevereiro de 2000 .

\begin{tabular}{lcccccc}
\hline Municípios & $\begin{array}{c}\text { Propriedades } \\
\text { amostradas }\end{array}$ & $\begin{array}{c}\text { Total de } \\
\text { amostras }\end{array}$ & $\begin{array}{c}\text { Total de } \\
\text { indivíduos }\end{array}$ & $\begin{array}{c}\text { Espécies }(\%)^{-1} \\
\text { flavopicta }\end{array}$ & $\begin{array}{c}\boldsymbol{Z} \text {. } \\
\text { fimbriolata }\end{array}$ & entreriana \\
\hline Barra do & 14 & 2.016 & 167.328 & 87 & 13 & 0 \\
$\begin{array}{l}\text { Bugres } \\
\text { Colíder }\end{array}$ & 21 & 1.260 & 70.560 & 81 & 19 & 0 \\
$\begin{array}{l}\text { Alta } \\
\text { Floresta }\end{array}$ & 15 & 1.125 & 42.750 & 72 & 28 & 0 \\
$\begin{array}{l}\text { São José do } \\
\text { Rio Claro }\end{array}$ & 17 & 1.632 & 62.016 & 72 & 28 & 0 \\
Juara & 27 & 1.377 & 99.144 & 51 & 37 & 12 \\
\hline
\end{tabular}

${ }^{1}$ Valores provenientes da média das percentagens de ocorrência da espécie considerada nas propriedades de cada município. 
aumento populacional da referida espécie de cigarrinha, como referem NILAKHE (1985) e FONTES et al. (1995).

Com base nos resultados obtidos no presente trabalho pode-se concluir que D. flavopicta e M. fimbriolata estão presentes em todos os municípios estudados, predominando a primeira espécie citada.

\section{REFERÊNCIAS BIBLIOGRÁFICAS}

COSENZA, G.W. et al. Resistência de gramíneas forrageiras a cigarrinha-das-pastagens. Pesquisa Agropecuária Brasileira, Brasília, v.24, n.8, p.961-968, 1989.

FONTES, E.G.; PIRES, C.S.S.; SUJII, E.R. Mixed risk-spreading strategies and the population dynamics of a Brazilian pasture pest, Deois flavopicta (Homoptera: Cercopidae). Journal of Economic Entomology, Lanham, v.88, n.5, p.1256-1262, 1995.

HEWITT, G.B. Ovipositional preferences of the spittlebug Zulia entreriana (Berg, 1879) and Deois flavopicta (Stal, 1854) (Homoptera: Cercopidae). Anais da Sociedade Entomológica do Brasil, Porto Alegre, v.14, n.2, p.197204, 1985.

HEWITT, G.B. Grazing management as a means of regulating spittlebug (Homoptera: Cercopidae) numbers in Central Brazil Pesquisa Agropecuária Brasileira, Brasília, v.23, n.7, p.697707, 1988.
KOLLER, W.W.; HONER, M.R. Desenvolvimento e sobrevivência de ninfas de cigarrinhas-das-pastagens (Homoptera: Cercopidae) sobre plantas de Brachiaria decumbens com diferentes características morfológicas. Anais da Sociedade Entomológica do Brasil, Londrina, v.23, n.2, p.163-170, 1994.

KOLLER, W.W.; VALÉRIO, J.R. Efeito da remoção da palha acumulada ao nível do solo sobre a população de cigarrinhas (Homoptera: Cercopidae) em pastagens de Brachiaria decumbens. Anais da Sociedade Entomológica do Brasil, Porto Alegre, v.17, n.1, p.209-215, 1988.

NILAKHE, S.S. Ecological observations on spittlebugs with emphasis on their occurrence in rice. Pesquisa Agropecuária Brasileira, Brasília, v.20, n.4, p.407-414, 1985.

PIRES, C.S.S.; PRICE, P.W.; OLIVEIRA, R.C. de. Distribution of the spittlebug Deois flavopicta Stal (Homoptera: Cercopidae) on wild and cultivated host species. Anais da Sociedade Entomológica do Brasil, Londrina, v.29, n.3, p.401-412, 2000 .

SALERMO, A.R. et al. Gramíneas forrageiras estivais perenes no Baixo Vale do Itajaí. Florianópolis : EMPASC, 1990. 99p.

SANTOS, J.P.; CRUZ, I.; BOTELHO, W. Avaliação de dano e controle da cigarrinha-das-pastagens em plantas de milho com diferentes idades. Sete Lagoas : EMBRAPA/ CNPMS, 1982. 9p. (Circular Técnica, 2). 